\title{
A Systematic Study of Acidic Peptides for b-Type Sequence Scrambling
}

\author{
A. Emin Atik, Talat Yalcin
}

Department of Chemistry, Faculty of Science, Izmir Institute of Technology, 35430 Urla-Izmir, Turkey

\begin{abstract}
A systematic study was carried out to examine the effects of acidic amino acid residues and the position of the acidic group on the cyclization of $b$ ions. The study utilized the model $C$-terminal amidated peptides XAAAAAA, AXAAAAA, AAXAAAA, AAAXAAA, AAAAXAA, AAAAAXA, AAAAAAX, XXAAAAAA, AAXXAAAA, AAAAXXAA, and AAAAAAXX, where $X$ is a glutamic acid (E) or aspartic acid (D) residue. The CID mass spectra of $b_{n}$ (where $n=7$ and 8 ) ions derived from XAAAAAA, AAAXAAA, AAAAAAX and XXAAAAAA, AAXXAAAA, AAAAXXAA, and AAAAAAXX exhibited very similar fragmentation patterns for both the glutamic and the aspartic acid peptide series. The CID mass spectra of $\mathrm{MH}^{+}$derived from model peptides presented substantial direct and non-direct sequence $b$ ions. The results indicate that $b$ ions produced from acidic peptides can also undergo head-to-tail cyclization, which is the reason for the formation of the non-direct sequence $b$ ions. The $b$ ion spectra derived from the peptides became more complex as the number of acidic residues in the peptides increased. Side chains of glutamic and aspartic acid did not inhibit the cyclization of the $b$ ions. Substantial water elimination was observed in all CID spectra of $b_{7}$ and $b_{8}$ ions. Finally, the preferential cleavage of glutamic or aspartic acid residues from macrocyclic structures of $b$ ions was also investigated under various collision energy conditions.
\end{abstract}

Key words: b-type sequence scrambling, Macrocyclization, Glutamic acid, Aspartic acid, Adjacent acidic residues

\section{Introduction}

$\mathrm{T}$ andem mass spectrometry with collision-induced dissociation, CID, is commonly used in proteomic studies to obtain the amino acid sequences of peptides. Understanding the structures of sequence ions and the fragmentation mechanisms for their formation is especially important in the de novo sequencing of peptides/proteins [1-3]. Protonated peptides typically fragment under low-energy CID conditions via cleavage at the amide bonds to give N-terminal $b$ ions and $a$ ions and C-terminal $y$ ions $[4,5]$, and these direct sequence ions

Electronic supplementary material The online version of this article (doi:10.1007/s13361-010-0018-3) contains supplementary material, which is available to authorized users.

Correspondence to: Talat Yalcin; e-mail: talatyalcin@iyte.edu.tr are used to derive the sequences of unknown peptides. The structures of $y$ ions have long been known to be truncated peptides $[6,7]$ but the structures of $b$ ions are still under intense scrutiny. Prior to $1995, b_{n}$ ions were assigned an acylium ion structure $[4,5]$. However, subsequent studies [8-12] suggested that $b_{n}(n=2-4)$ ions have a protonated oxazolone structure. In addition, infrared spectroscopy experiments have clearly indicated an oxazolone structure for $b_{2}$ ions from doubly protonated tryptic peptides [13]. Diketopiperazine structures have also been postulated as structures for $b_{2}$ ions [14]. Recently, Wysocki and coworkers indicated that the $b_{2}$ ion obtained from HA has a mixture of oxazolone and diketopiperazine structures [15]. Infrared multiphoton dissociation (IRMPD) experiments combined with theoretical studies also demonstrated that $b_{4}$ ions derived from Leu-enkephalin (YGGFL) have an oxazolone structure $[16,17]$. A review paper related to

Received: 2 August 2010

Revised: 8 October 2010

Accepted: 9 October 2010

Published online: 27 January 2011 
peptide fragmentation mechanisms was reported by Paizs and Suhai [18].

In early low-energy CID studies, the non-direct sequence ions were reported without stating the macrocyclic structure of the $b$ ions $[19,20]$. It was pointed out that, due to intramolecular rearrangements in trap instruments, nondirect sequence ions may complicate the interpretation of CID mass spectra. More recent detailed studies [21-25] have shown that $b_{n}$ ions $(n=5,6,7 \ldots)$ undergo cyclization through the attack of the free N-terminal amino group on the charged C-terminal oxazolone ring to form a macrocyclic intermediate. This macrocyclic structure re-opens at different amide bonds as a result of the mobile proton on the ring to form linear $b$ isomers that contain various C-terminal oxazolones. As a result, the original primary sequence of the peptide is scrambled, which generates non-direct sequence fragments in product ion mass spectra.

Recently, direct evidence for a macrocyclic structure of the $b_{5}$ ion from $\mathrm{G}_{5} \mathrm{R}$ has been obtained from IRMPD experiments and density functional theory calculations [26]. Additionally, ion mobility mass spectrometry (IM-MS) studies have supported the macrocyclic structure of $b$ ions, as a result of the similarity of the collision cross-sections of the $b_{5}$ ions obtained from YAGFL- $\mathrm{NH}_{2}$ and protonated cyclo-YAGFL [27]. Van Stipdonk and coworkers have studied the influence of the size of the $b$ ion fragment on sequence scrambling [28]. It was stated that the formation of macrocyclic $b$ ions for larger peptides, such as hepta-, octa-, and nonapeptides, is entropically disfavored. Harrison published a detailed study on the cyclization of peptide $b_{9}$ ions [29]. It was shown that the product ion mass spectra of $b_{9}$ ions derived from $\mathrm{YA}_{9}, \mathrm{~A}_{4} \mathrm{YA}_{5}$, and $\mathrm{A}_{8} \mathrm{YA}$ are almost identical, which is direct evidence of a cyclization reaction and the sequence scrambling of the $b_{9}$ ion before fragmentation. More recently, Harrison et al. [30] reported that the position of the histidine residue is important for the macrocyclization of $b_{5}$ ions produced from peptides containing the basic His residue. It was shown that if the histidine residue is close to the N-terminal position, no clear evidence for cyclization is observed; however, when the histidine residue gets closer to the C-terminal position, sequence scrambling is observed. They have clearly shown the effect of the position of the histidine residue on the cyclization of $b$ ions. In addition, Van Stipdonk et al. [31] reported that arginine-containing peptides show only direct sequence $b$ ions or the ions that are related to the arginine side chain. They did not observe any related non-direct sequence $b$ ions.

In this work, we carried out a systematic study to examine the effects of acidic amino acids (glutamic or aspartic acid) on the cyclization of peptide $b$ ions. In addition, the effect of the position of the acidic group in the peptide was studied. The study utilized two sets of model peptides. The first set was composed of six alanine residues and one glutamic or aspartic acid residue (heptapeptides), where the position of the acidic residue was varied. The second set was comprised of six alanine residues with two adjacent glutamic or aspartic acid residues (octapeptides), where the position of the acidic amino acid was changed. All peptides were C-terminal amides rather than free acids.

\section{Experimental}

The C-terminal amidated synthetic model peptides were purchased from GL Biochem Ltd. (Shanghai, China) and used as received. HPLC-grade methanol and formic acid were used throughout the experiment. Peptides were dissolved in a $1: 1(\mathrm{v} / \mathrm{v})$ mixture of $\mathrm{MeOH}$ and deionized $\mathrm{H}_{2} \mathrm{O}$ to give a concentration of $10^{-3}$ or $10^{-4} \mathrm{M}$.

Two different mass spectrometer systems were used throughout the experiments. An LTQ XL linear ion-trap mass spectrometer (Thermo Finnigan, San Jose, CA, USA) equipped with an ESI source was used for the product ion mass spectra of $b$ ions in order to demonstrate $b$-type sequence scrambling of acidic peptides. Before each experiment, the instrument was calibrated with the company's calibration mixture (Calmix: caffeine, MRFA, and Ultramark). The experimental settings (multipole, lens voltages, etc.) were optimized for maximum $\mathrm{MH}^{+}$signal with the LTQ Tune software. The spray voltage was $+5.0 \mathrm{kV}$ and the $\mathrm{N}_{2}$ sheath gas flow rate was 10 (arbitrary units). The capillary temperature was maintained at $275{ }^{\circ} \mathrm{C}$ and the capillary voltage at $21 \mathrm{~V}$. Helium was used as the collision gas for CID and as a bath/buffer gas to improve trapping efficiency. A $100 \mu \mathrm{M}$ peptide solution was prepared in 50:50:1 $(\mathrm{v} / \mathrm{v} / \mathrm{v}) \mathrm{MeOH} / \mathrm{H}_{2} \mathrm{O} / \mathrm{HCOOH}$ and introduced into the ion source with an incorporated syringe pump at a flow rate of $5 \mu \mathrm{L} \mathrm{min}{ }^{-1}$. The CID conditions for peptide fragmentations were as follows. Normalized collision energy was set at between 19 and $23 \%$ with an activation $(q)$ of 0.250 , and an activation time of $30 \mathrm{~ms}$ was applied at each CID stage. The isolation width $(\mathrm{m} / \mathrm{z})$ for precursor ions was set at between 1.2 and 1.8 for both $\mathrm{MS}^{2}$ and $\mathrm{MS}^{3}$ acquisitions, and at least 500 scans were averaged, with a scan rate of 1 employed.

For the breakdown graphs, a hybrid triple quadrupole/ linear ion trap instrument (4000 Q-TRAP, Applied Biosystems/MDS Sciex, Concord, Canada) equipped with a turbo ion spray source was used. Nitrogen gas was used as nebulizer, curtain, and collision gases during the experiments. Model peptide solutions at a concentration of $10 \mu \mathrm{M}$ were introduced into the system with an infusion pump at a flow rate of $5 \mu \mathrm{L} \mathrm{min}^{-1}$. MS/MS data for $\mathrm{MH}^{+}$were acquired in enhanced product ion scan mode, and the ion spray voltage was $+5.5 \mathrm{kV}$. The collision energy was varied from 18 to $36 \mathrm{eV}$ in increments of $2 \mathrm{eV}$, and at least 40 cycles were averaged, with a scan rate of $1000 \mathrm{Da} / \mathrm{s}$ employed. 


\section{Results and Discussion}

\section{Effect of b-Type Sequence Scrambling on $\mathrm{MH}^{+}$ Product Ion Mass Spectra}

The breakdown graphs of $\mathrm{MH}^{+}$produced from XAAAAAA, AAAXAAA, AAAAAAX, XXAAAAAA, AAXXAAAA, AAAAXXAA, and AAAAAAXX (where $\mathrm{X}=\mathrm{E}$ or $\mathrm{D}$ ) are shown in Figure S1 to S7 of the Electronic Supplementary Material (ESM), respectively. It is clearly seen that every MS/MS spectrum consists of both direct and non-direct sequence fragment ions during low-energy CID studies. However, the abundance of scrambled $b$ ions is low in the MS/MS spectra of $\mathrm{MH}^{+}$, so they do not complicate the spectra very much at low-energy CID conditions. As an example, the product ion mass spectrum of $\mathrm{MH}^{+}$derived from EAAAAAA- $\mathrm{NH}_{2}$ is shown in Figure S8.

\section{b-Type Sequence Scrambling of Glutamic or Aspartic Acid Containing Heptapeptides}

The CID mass spectra of $b_{7}$ ions obtained from $\mathrm{EA}_{6}, \mathrm{~A}_{3} \mathrm{EA}_{3}$, and $\mathrm{A}_{6} \mathrm{E}$ are identical, as Figure 1 illustrates. The dominant fragment ion is $b_{7}^{\circ}\left(\mathrm{b}_{7}-\mathrm{H}_{2} \mathrm{O}\right.$ at $m / z$ 538) in the CID spectra of $b_{7}$, while the intensity of glutamic acid residue loss from the $b_{7}$ ion is about $15 \%$. Also, the CID mass spectra of the $b_{7}$ ions obtained from $\mathrm{DA}_{6}, \mathrm{~A}_{3} \mathrm{DA}_{3}$, and $\mathrm{A}_{6} \mathrm{D}$ are identical (as shown in Figure 2), and the intensity of aspartic acid residue loss from $b_{7}$ ions is about $35 \%$. Again, the $b_{7}-\mathrm{H}_{2} \mathrm{O}$ $\left(b_{7}{ }^{\circ}, m / z 524\right)$ ion is the most abundant peak in the CID spectra of $b_{7}$. It is obvious that the dominant fragment ion is $b_{7}{ }^{\circ}$, which results from the elimination of water from $b_{7}$ ions from both glutamic and aspartic acid containing heptapeptides due to the presence of $-\mathrm{OH}$ groups on the side chains of acidic residues. Detailed studies of water loss from the
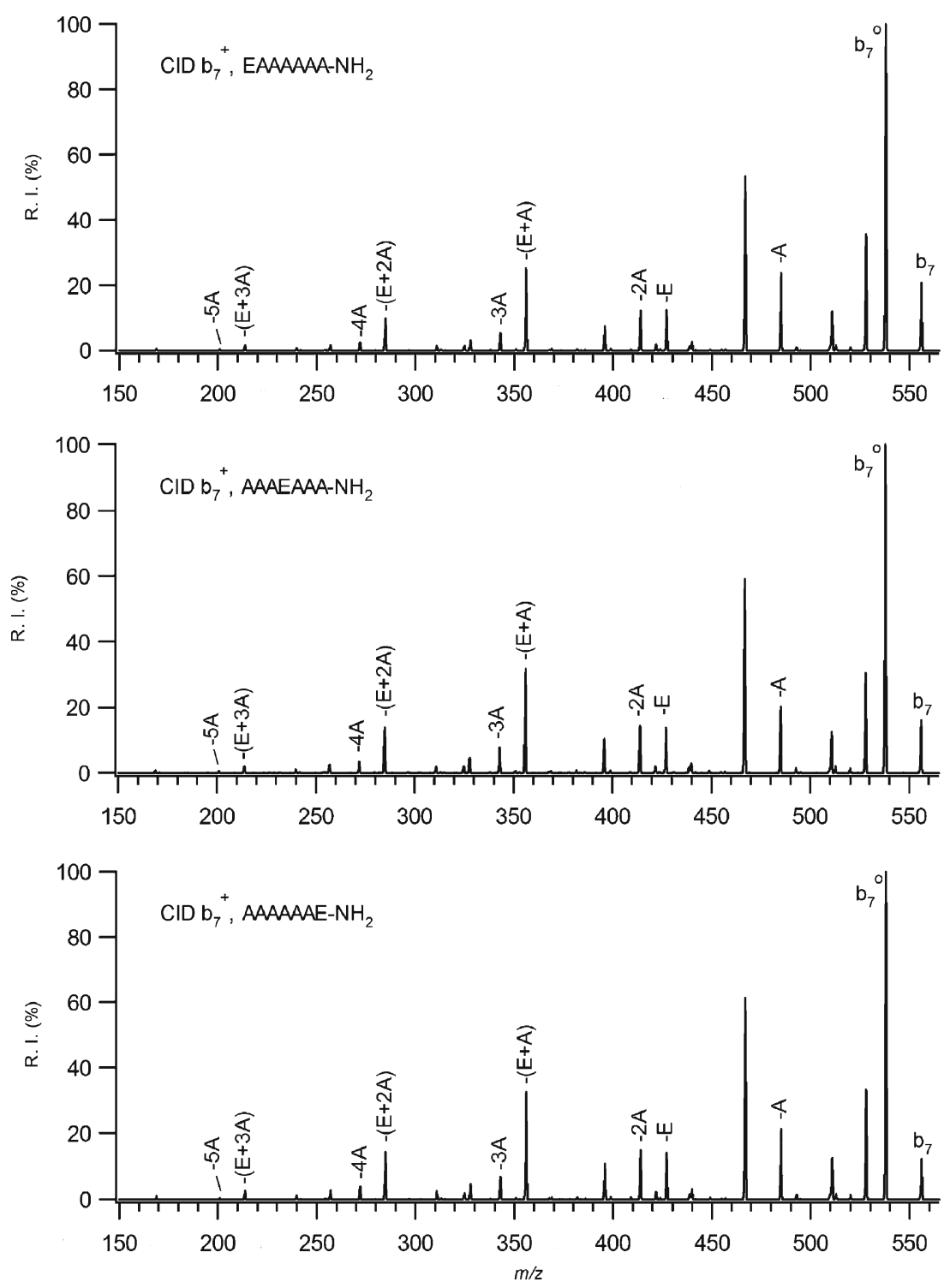

Figure 1. Comparison of the CID mass spectra of $b_{7}$ ions derived from $E A_{6}, A_{3} E A_{3}$, and $A_{6} E$ 

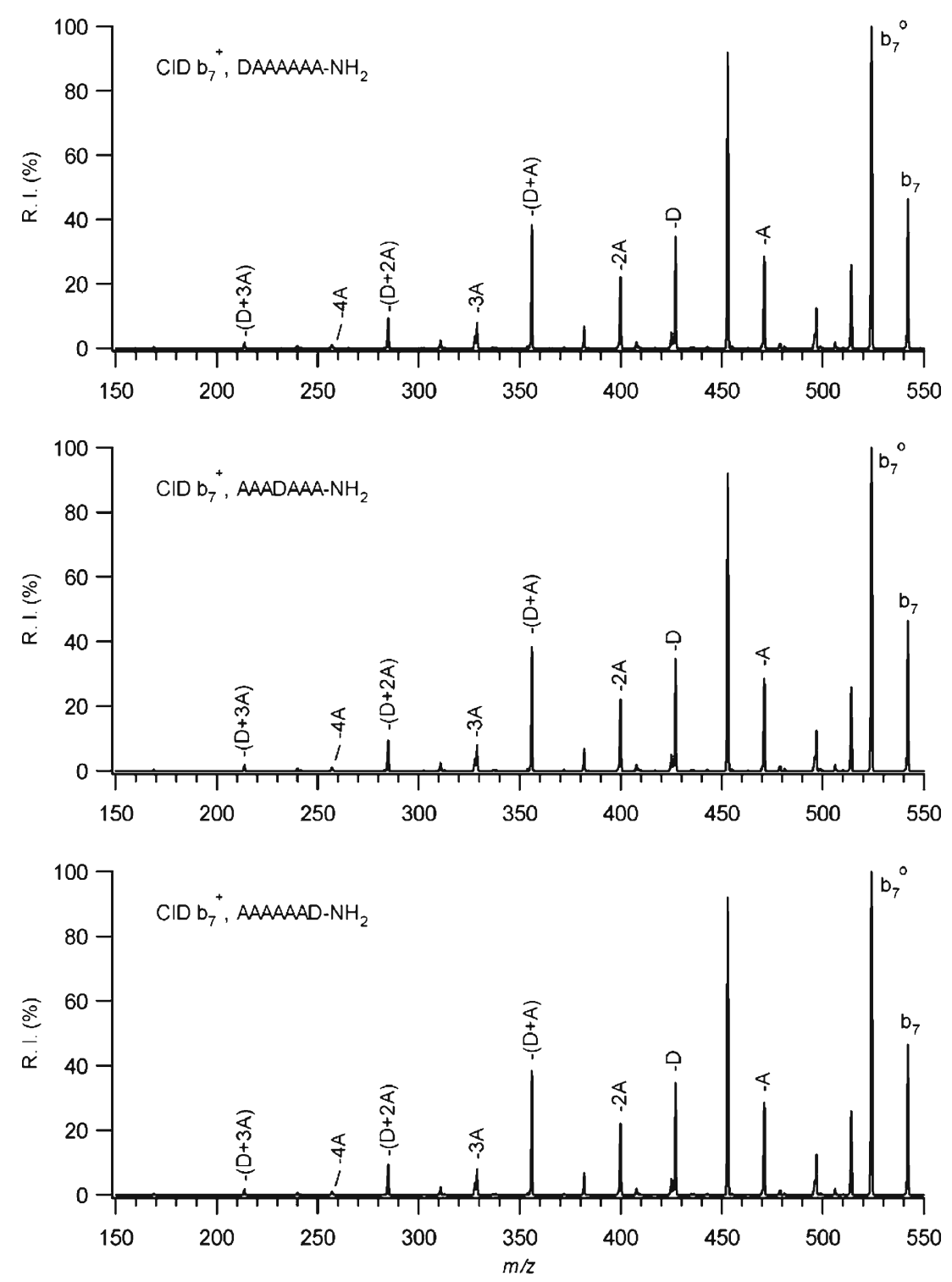

Figure 2. Comparison of the CID mass spectra of $b_{7}$ ions derived from $D A_{6}, A_{3} D A_{3}$, and $A_{6} D$

backbones of protonated peptides have been carried out by the O'Hair and Gaskell groups [32, 33]. Surprisingly, the elimination of one alanine residue and water $\left(\mathrm{A}+\mathrm{H}_{2} \mathrm{O}\right)$ from $b_{7}$ leads to an intensity that is as strong as that from $b_{7}-$ $\mathrm{H}_{2} \mathrm{O}$ for the aspartic acid containing heptapeptides. (The other fragment ions in the $b_{7}$ spectra from either glutamic or aspartic acid containing heptapeptides are given with assignments in the ESM).

The product ion MS/MS spectra for $b_{7}$ ions derived from seven isomeric heptapeptides containing either glutamic or aspartic acid residues are identical (all seven $b_{7}$ mass spectra for glutamic and aspartic acid containing heptapeptides are shown in Figure S9 and S10 of the ESM, respectively). Non-direct sequence ion eliminations are observed for $b_{7}$ as a result of the sequence scrambling of $b$ ions of acidic peptides under the experimental conditions in the ion trap mass spectrometer. In addition to $b_{7}$, the $b_{6}$ ions obtained from $\mathrm{XA}_{6}, \mathrm{AXA}_{5}, \mathrm{~A}_{2} \mathrm{XA}_{4}$,
$\mathrm{A}_{3} \mathrm{XA}_{3}, \mathrm{~A}_{4} \mathrm{XA}_{2}$, and $\mathrm{A}_{5} \mathrm{XA}$ heptapeptides (where $\mathrm{X}=\mathrm{E}$ or $\mathrm{D}$ ) exhibit near-identical MS/MS spectra (Figure S11 and S12 of the ESM). Substantial water elimination is observed for all peptides in the CID mass spectra of $b_{7}$ and $b_{6}$ ions. It is clearly apparent that side chains of either glutamic or aspartic acid do not prevent the macrocyclization of $b$ ions.

The second most intense fragment ion in the MS/MS spectrum of the $b_{7}$ ion obtained from EAAAAAA- $\mathrm{NH}_{2}$ derives from the elimination of $\mathrm{A}+\mathrm{H}_{2} \mathrm{O}$ to form an ion with $\mathrm{m} / \mathrm{z}$ 467. In order to investigate the source of this fragment ion, precursor ion scanning analysis was performed on the Q-TRAP mass spectrometer (see Figure 3). There are five possible sources of this ion: it may come directly from $\mathrm{MH}^{+}\left(\mathrm{m} / z\right.$ 573), and/or from $b_{7}$ ( $m / z$ 556), and/or from $\mathrm{MH}^{+}-\mathrm{H}_{2} \mathrm{O}(\mathrm{m} / z$ 555), and/or from $b_{7}^{\circ}(\mathrm{m} / \mathrm{z} 538)$, and/or from $b_{7}-\mathrm{A}(\mathrm{m} / \mathrm{z} 485)$. These five pathways are illustrated in Scheme 1. 


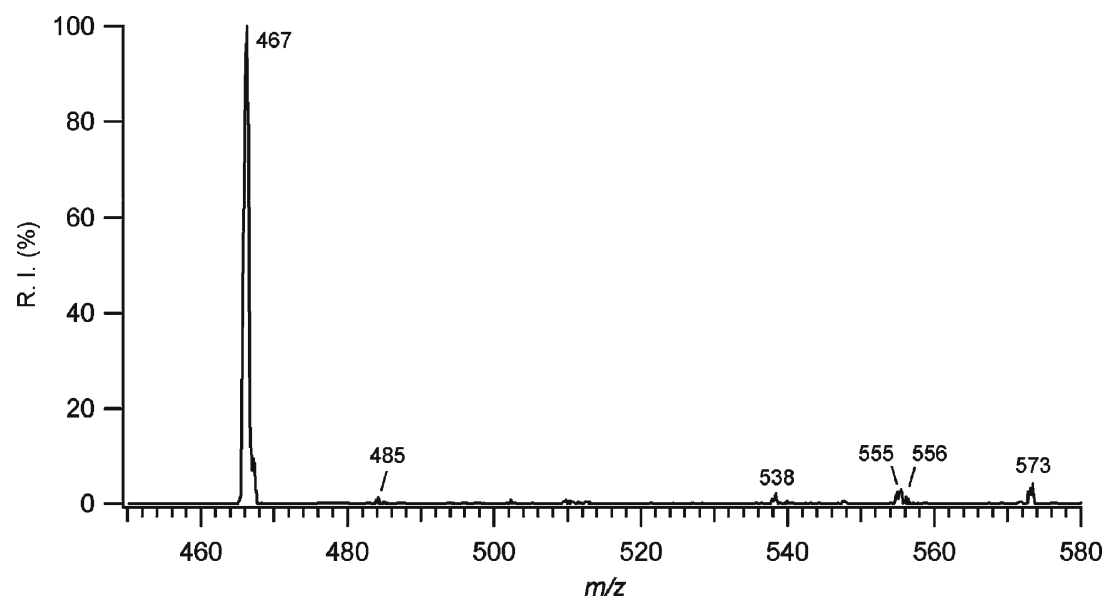

Figure 3. Precursor ion mass spectra of the $\mathrm{m} / \mathrm{z} 467$ ion derived from EAAAAAA- $\mathrm{NH}_{2}$

\section{b-Type Sequence Scrambling of Octapeptides} Containing Two Adjacent Glutamic or Aspartic Acid Residues

The second set contained six alanine residues with two adjacent glutamic or aspartic acid residues, and eight model peptides were designed on this basis, namely EEAAAAAA, AAEEAAAA, A A A AEEAA, AAAAAAEE, DDAAAAAA, AADDAAAA, AAAADDAA, and AAAAAADD (all C-terminal amides), in order to examine the effects of the occurrence of two adjacent acidic residues on $b$-type sequence scrambling. The CID mass spectra of the $b_{8}$ ions originating from octapeptides with two glutamic acid residues (shown in Figure 4) are nearly identical. In addition, the relative intensities arising from the elimination of one alanine residue and one glutamic acid residue are almost equal (18\%). The intensities arising from the elimination of two glutamic acid residues are all about $24 \%$ in the CID spectra of the $b_{8}$ ions for the first three octapeptides, although this intensity is higher $(\sim 35 \%)$ for $\mathrm{A}_{6} \mathrm{E}_{2}$. The strongest peak is from $b_{8}-\mathrm{H}_{2} \mathrm{O}\left(b_{8}{ }^{\circ}, \mathrm{m} / z\right.$ 667) in the CID spectra of $b_{8}$. In the same manner, it is apparent that the CID mass spectra of the $b_{8}$ ions obtained from octapeptides with two adjacent aspartic acid residues (shown in Figure 5) are nearly identical. In the $b_{8}$ product ion mass spectra for the first three octapeptides, the intensity arising from the elimination of two aspartic acid residues is about $34 \%$, but it is nearly $55 \%$ for the octapeptide $\mathrm{A}_{6} \mathrm{D}_{2}$. Additionally, the intensities corresponding to the loss of one alanine and one aspartic acid

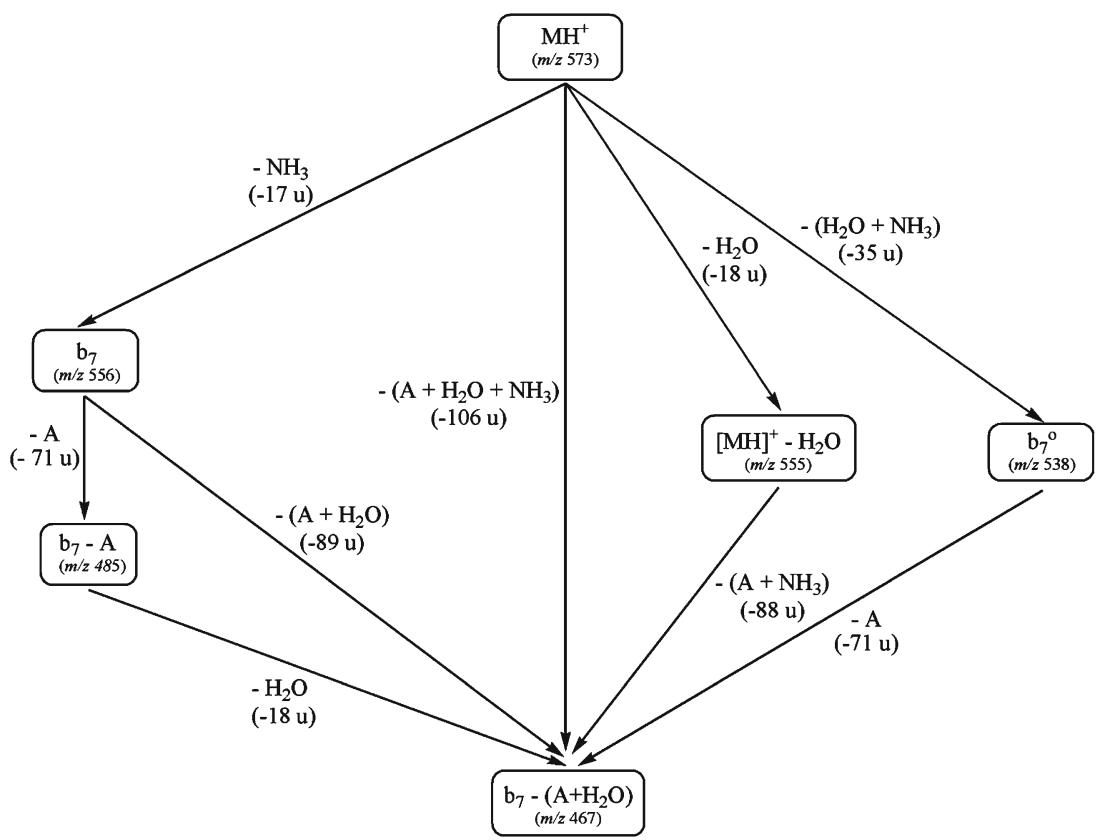

Scheme 1. Sources of the elimination of $A+\mathrm{H}_{2} \mathrm{O}$ from the $b_{7}$ ion of EAAAAAA-NH $\mathrm{H}_{2}$ 

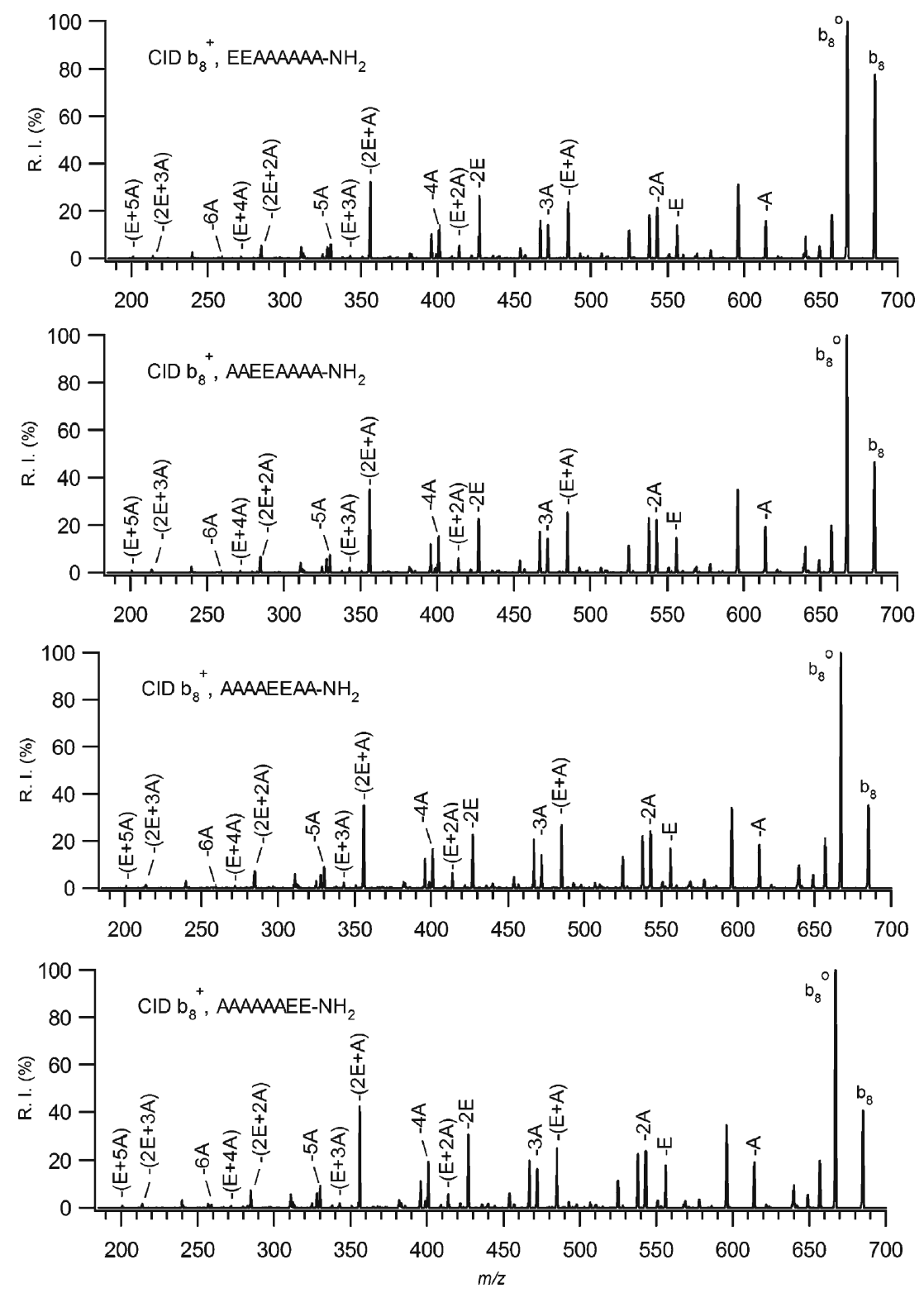

Figure 4. Comparison of the CID mass spectra for $b_{8}$ ions derived from $E_{2} A_{6}, A_{2} E_{2} A_{4}, A_{4} E_{2} A_{2}$, and $A_{6} E_{2}$

residue are nearly $25 \%$ and $45 \%$, respectively, in the $b_{8}$ CID mass spectrum. Again, the loss of water from $b_{8}(\mathrm{~m} / z$ 639) yields the strongest fragment peak in the CID mass spectrum of $b_{8}$. (The other fragment ions in the $b_{8}$ spectra from octapeptides with either two adjacent glutamic or two adjacent aspartic acid residues are given with assignments in the ESM). As a result, it is clear that the presence of two adjacent acidic amino acid residues does not prevent the macrocyclization of $b$ ions.

The elimination of water from the backbones of protonated peptides was reported by the O'Hair and Gaskell groups in detail $[32,33]$. In addition to this, in the present study, due to the existence of glutamic or aspartic acid residues in model peptides, we proposed that water was eliminated from the side chains of these acidic residues. The mechanisms for the elimination of water from the $b_{8}$ ion and the formation of $b_{8}$ macrocyclic structure are shown for one isomer, AAEEAAAA- $\mathrm{NH}_{2}$, in Scheme 2. The $b_{8}$ (linear oxazolone) ion, AAEEAAAA $A_{\text {oxa }}$, can follow two paths: either the elimination of water from a side chain via path 1 , or the formation of a macrocyclic $b$ ion via path 2 . After proton transfer from the oxazolone ring to the amide nitrogen of the first glutamic acid residue, water elimination can occur with the formation of an internal pyroglutamic ring. A second mechanism for water elimination can also occur through the formation of either a second internal fivemembered (pyroglutamic) ring or a six-membered ring.

The macrocyclic $b_{8}$ ion can follow eight possible ringopening pathways to form isomeric linear oxazolones, as shown in Scheme 3. Each labeled fragment ion in the MS/ MS spectrum of $b_{8}$ represents the loss of alanine and/or 

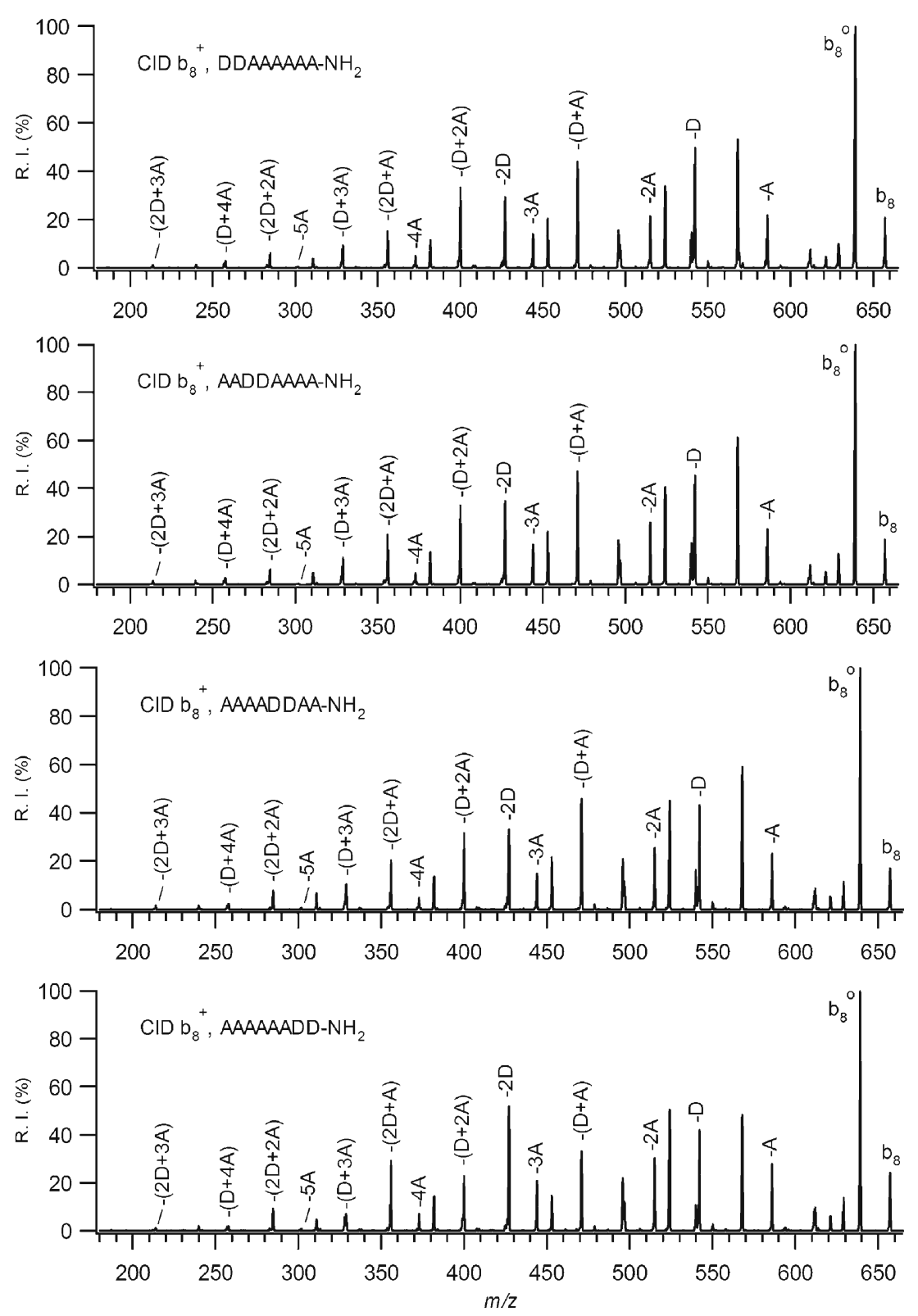

Figure 5. Comparison of the CID mass spectra of $b_{8}$ ions derived from $D_{2} A_{6}, A_{2} D_{2} A_{4}, A_{4} D_{2} A_{2}$, and $A_{6} D_{2}$

glutamic acid residues, and the eliminations from each linear isomer are shown in Scheme 3.

\section{Effect of Acidic Residue Position in the Peptide on the Macrocyclization of $b_{n}(n=7$ or 8$)$ Ions}

Van Stipdonk et al. [34] studied whether acidic, basic, and amide side chains have any effect on macrocyclic $b_{5}$ ion formation from YAXFLG (where $\mathrm{X}=\mathrm{E}, \mathrm{D}, \mathrm{K}, \mathrm{Q}$, and $\mathrm{N}$ ) model peptides. They considered only a single acidic residue (glutamic or aspartic acid), located at the third position in the peptide. In this study, we not only show the macrocyclization of $b$ ions produced from acidic peptides, but we also investigate the dependence of macrocyclization on the position(s) of the acidic residue(s) in isomeric hepta- and octapeptides. The positions of the acidic residues in the peptides could affect the scrambling chemistry of $b$ ions, in line with recent work [30] on the effect of the His residue on the cyclization of $b$ ions. In that paper, it was shown that there is less evidence for the cyclization of $b_{5}$ ions derived from $\mathrm{HA}_{5}$ and $\mathrm{AHA}_{4}$ in their CID spectra; however, the formation of non-direct sequence ions is more evident due to the scrambling chemistry when the histidine residue is close to the C-terminus. This is why the macrocyclization cannot be generalized based on the investigation of a single peptide containing a single acidic residue at the third position. In our study, the effects of the presence of single and adjacent acidic residues in the peptide isomers were investigated in detail. It was shown that identical CID mass spectra were obtained for hepta- and octapeptides containing single 


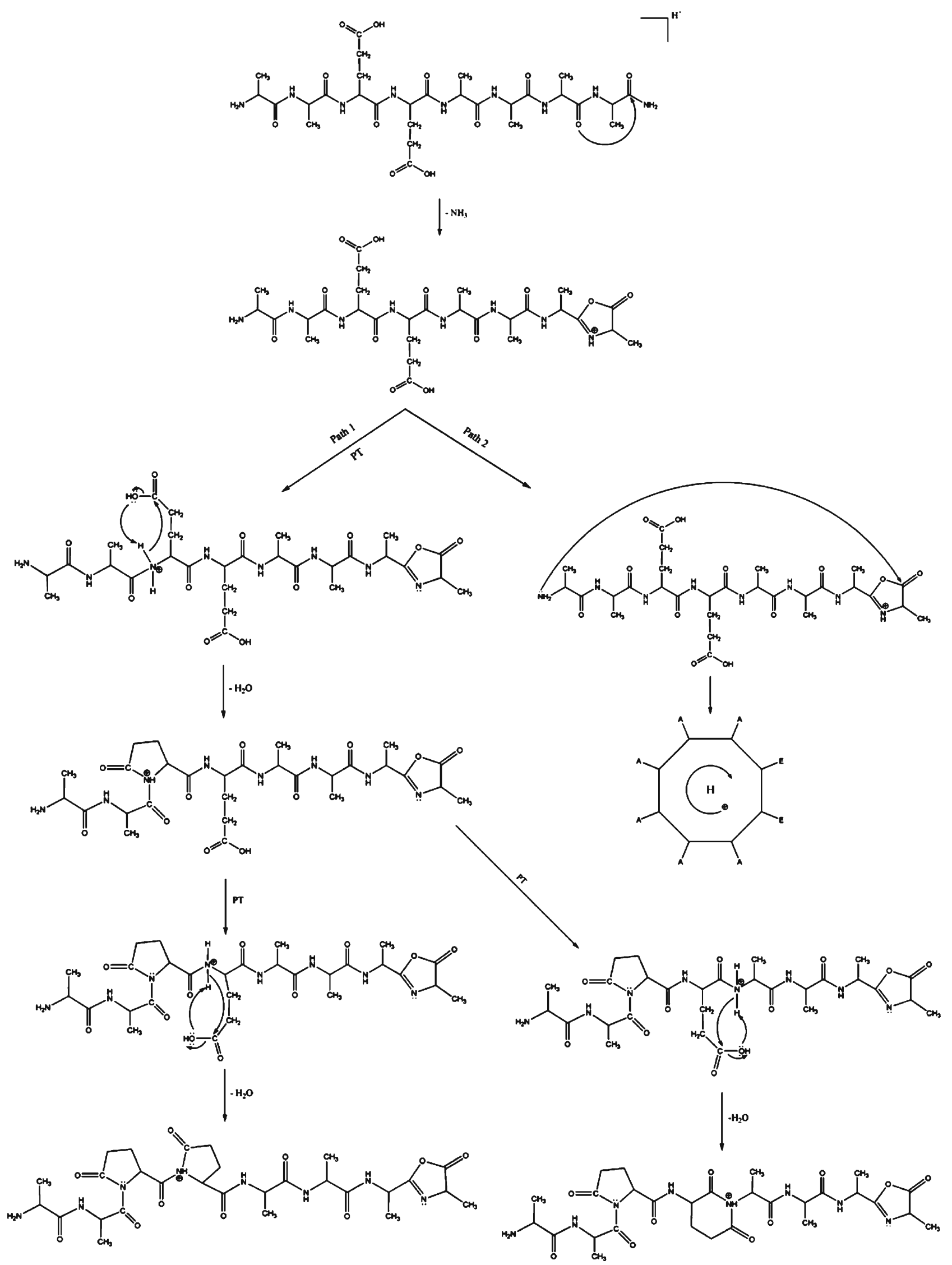

Scheme 2. The proposed mechanisms for the elimination of water from the $b_{8}$ ion and the formation of $b_{8}$ macrocyclic structure for AAEEAAAA- $\mathrm{NH}_{2}$ 


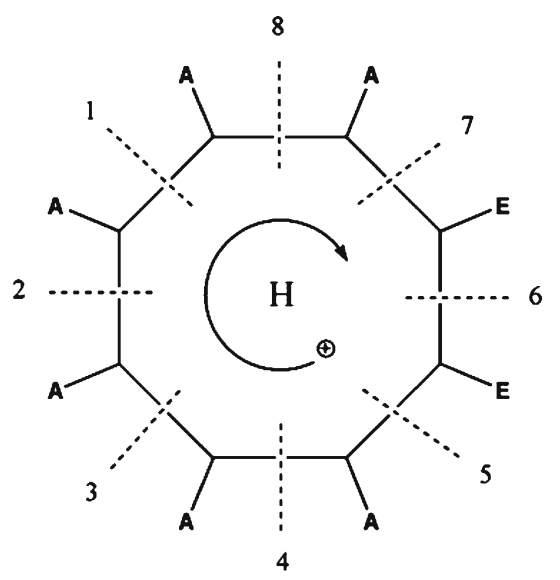

\begin{tabular}{|c|c|c|c|c|c|c|c|}
\hline Path 1 & Path 2 & Path 3 & Path 4 & Path 5 & Path 6 & Path 7 & Path 8 \\
\hline AAAAEEAA $_{\text {oxa }}$ & AAAEEAAA $_{\mathrm{oxa}}$ & AAEEAAAA $_{\mathrm{oxa}}$ & AEEAAAAA $_{\mathrm{oxa}}$ & EEAAAAAA & EAAAAAAE $_{\mathrm{oxa}}$ & AAAAAAEE $_{\text {oxa }}$ & AAAAAEEA $_{\text {oxa }}$ \\
\hline$\downarrow-A$ & $\downarrow-A$ & $\downarrow-A$ & $\downarrow-A$ & $\downarrow-A$ & $\downarrow-E$ & $\downarrow^{-E}$ & $\downarrow-A$ \\
\hline AAAAEEA ${ }_{\text {oxa }}$ & AAAEEAA $_{\text {oxa }}$ & AAEEAAA $_{\text {oxa }}$ & AEEAAAA $_{\text {oxa }}$ & EEAAAAA $_{\text {oxa }}$ & EAAAAAA $_{\text {oxa }}$ & AAAAAAE $_{\text {oxa }}$ & AAAAAEE $_{\mathrm{oxa}}$ \\
\hline$\downarrow-A$ & $\downarrow-A$ & $\downarrow-A$ & $\downarrow-A$ & $\downarrow-A$ & & $\downarrow-E$ & $\downarrow-E$ \\
\hline AAAAEE $_{\text {oxa }}$ & AAAEEA $_{\text {oxa }}$ & AAEEAA $_{\text {oxa }}$ & AEEAAA $_{\text {oxa }}$ & EEAAAA $_{\text {oxa }}$ & EAAAAA $_{\text {oxa }}$ & $\mathrm{AAAAAA}_{\mathrm{oxa}}$ & AAAAAE $_{\text {oxa }}$ \\
\hline$\downarrow_{\text {AAAAE }_{\text {oxa }}}^{\downarrow^{-E}}$ & $\downarrow_{\text {AAAEE }_{\text {oxa }}}^{-\mathrm{A}}$ & $\downarrow_{\text {AAEEA }_{\text {oxa }}}^{-A}$ & $\downarrow_{\text {AEEAA }_{\text {oxa }}}^{-A}$ & $\downarrow_{\text {EEAAA }_{\mathrm{OSa}}}^{-\mathrm{A}}$ & $\downarrow_{\text {EAAAA }_{\text {oxa }}}^{-\mathrm{A}}$ & $\downarrow_{\mathrm{AAAAA}_{\mathrm{OXa}}}^{-\mathrm{A}}$ & $\downarrow_{\mathrm{AAAAA}_{\mathrm{oxa}}}^{\downarrow^{-E}}$ \\
\hline$\downarrow-E$ & $\downarrow-E$ & $\downarrow-A$ & $\downarrow-A$ & $\downarrow-A$ & $\downarrow-A$ & $\downarrow-A$ & $\downarrow-A$ \\
\hline AAAA $_{\text {oxa }}$ & AAAE $_{\mathrm{oxa}}$ & $\mathrm{AAEE}_{\mathrm{O} \mathrm{X}}$ & $\mathrm{AEEA}_{\mathrm{oxa}}$ & EEAA $_{\text {oxa }}$ & EAAA $_{\text {oxa }}$ & AAAA $_{\text {oxa }}$ & AAAA $_{\text {oxa }}$ \\
\hline$\downarrow-A$ & $\downarrow-E$ & $\downarrow-E$ & $-A$ & $\downarrow-A$ & $\downarrow-A$ & $\downarrow-A$ & $\downarrow-A$ \\
\hline \multirow[t]{3}{*}{$\mathrm{AAA}_{\mathrm{oxa}}$} & $\mathrm{AAA}_{\mathrm{oxa}}$ & $\mathrm{AAE}_{\mathrm{oxa}}$ & $\mathrm{AEE}_{\mathrm{oxa}}$ & $\mathrm{EEA}_{\mathrm{oxa}}$ & $\mathrm{EAA}_{\mathrm{oxa}}$ & $\mathrm{AAA}_{\mathrm{oxa}}$ & $\mathrm{AAA}_{\text {oxa }}$ \\
\hline & & & $\downarrow^{-E}$ & $1-\mathbf{A}$ & $\downarrow^{-A}$ & & \\
\hline & & & $\mathrm{AE}_{\text {oxa }}$ & $\mathrm{EE}_{\text {oxa }}$ & $\mathrm{EA}_{\text {oxa }}$ & & \\
\hline
\end{tabular}

Scheme 3. The macrocyclic $b_{8}$ ion and eight possible ring-opening pathways

glutamic or aspartic acid residue(s) (Figure 1, 2, 4, and 5). It can be concluded that the macrocyclization of $b$ ions does not depend on the position(s) of the acidic residue(s) in the hepta- or octapeptide series.

\section{Collision Energy Dependence of the Preferential} Cleavage of Glutamic or Aspartic Acid Residue(s) from the $b_{n}$ Macrocyclic Structure

It is well known that the selective opening of $b_{5}$ cyclic ions derived from the peptide YAXFLG follows the trend: $Q>$ $\mathrm{K}>\mathrm{D}>\mathrm{N} \sim \mathrm{E}$ [34]. However, in the current work, we studied the preferential cleavage of glutamic or aspartic acid residue (s) from the macrocyclic structures of $b_{n}$ ions (where $n=7$ or 8 ) in order to evaluate its dependence on collision energy. The preferential cleavage of glutamic or aspartic acid residues from macrocyclic $b_{7}$ ions is shown in Figure 6a (only glutamic or aspartic acid elimination was considered for the purposes of comparison). It is apparent that aspartic acid cleavage from the cyclic structure is favored under lowenergy CID conditions rather than glutamic acid residue cleavage. However, when the collision energy is increased from 18 to $25 \mathrm{eV}$, the preferential cleavage of glutamic acid becomes more favorable than aspartic acid residue loss in the heptapeptide series. In addition, preferential aspartic acid cleavage started to decrease sharply above $20 \mathrm{eV}$, while the preferential cleavage of the glutamic acid residue also started to decrease after $25 \mathrm{eV}$. Similarly, the preferential cleavages of acidic residue(s) from macrocyclic $b_{8}$ ions are shown in Figure $6 \mathrm{~b}$. The preferential cleavage of one aspartic acid residue from the $b_{8}$ ion decreased dramatically as the collision energy increased. However, the preferential cleavage of glutamic acid increased as the collision energy increased up to $26 \mathrm{eV}$, after which it decreased. The preferential loss of two adjacent glutamic acid residues has nearly the same profile as the preferential loss of two adjacent aspartic acid residues up to $26 \mathrm{eV}$; both show small increases in their intensities up to $26 \mathrm{eV}$. Above $26 \mathrm{eV}$, the intensity of the selective loss of two glutamic acid residues adopts a steady-state profile, while the preferential cleavage of two aspartic acid residues decreases. Based on the results discussed above, preferential acidic residue cleavage definitely depends on the collision energy, and the order of residue cleavage preference can be changed. 

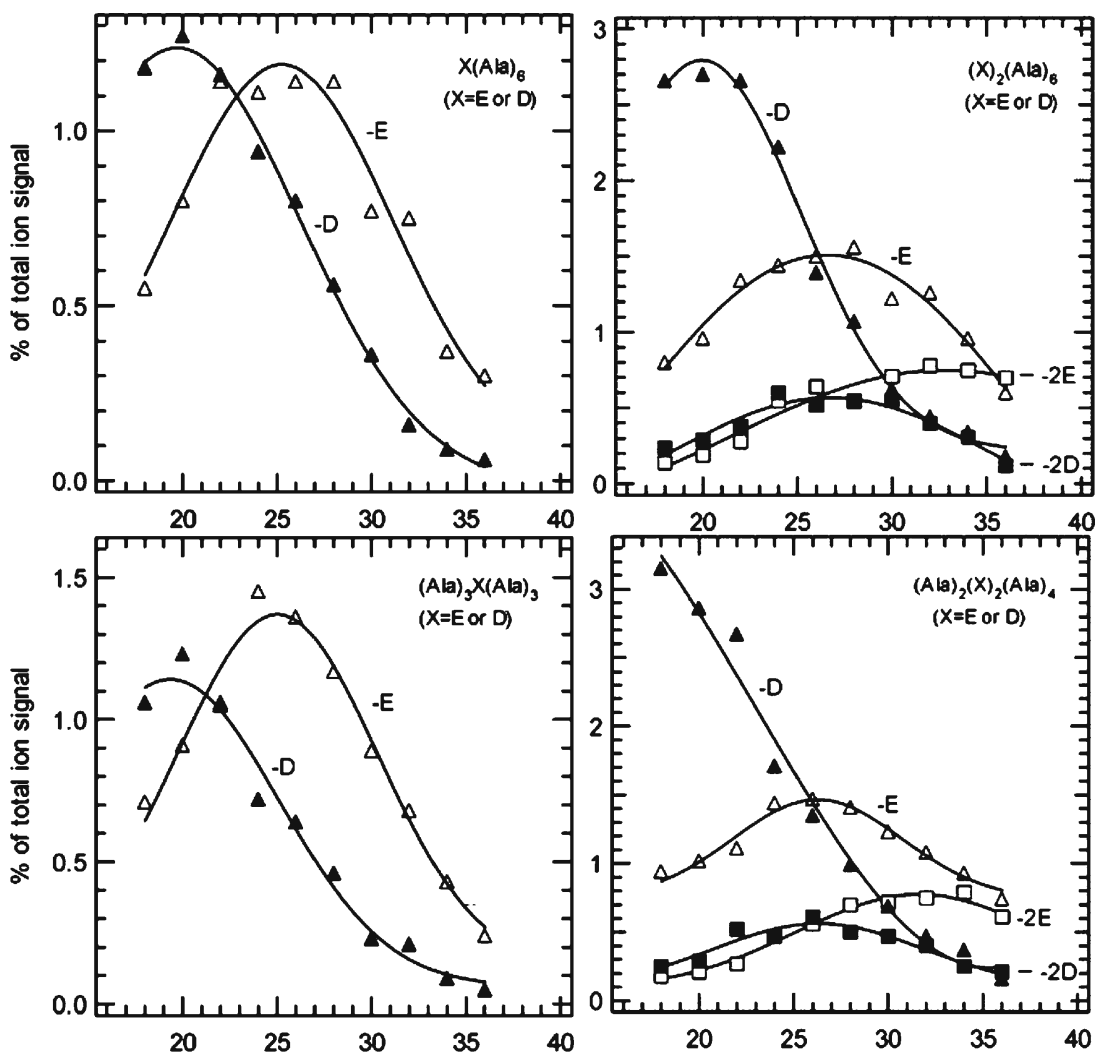

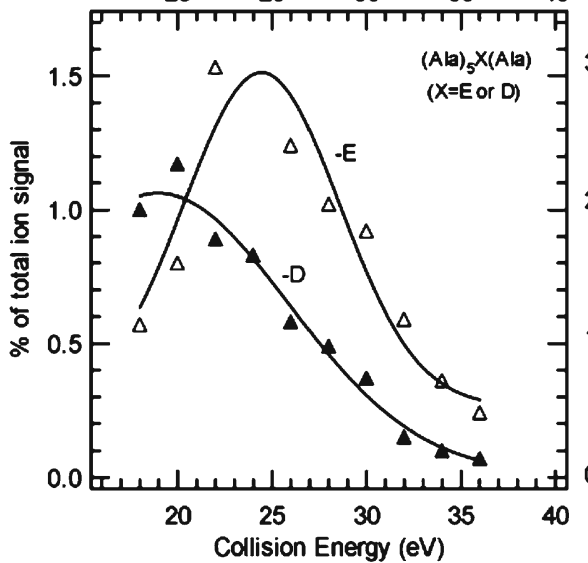

(a)

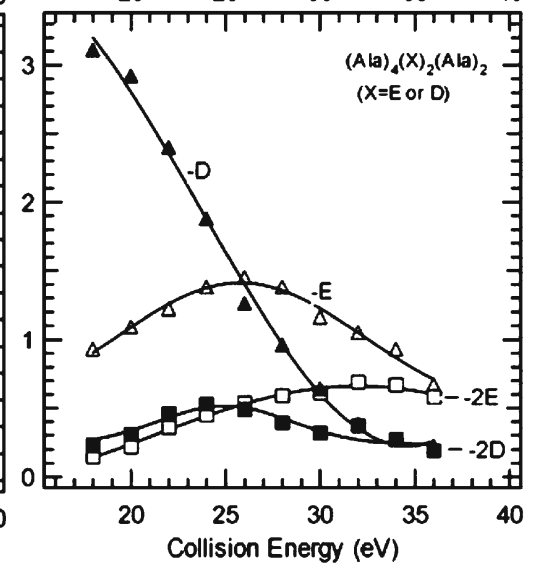

(b)

Figure 6. (a) Comparison of the preferential cleavage of a glutamic or aspartic acid residue from the $b_{7}$ ions of $X A_{6}, A_{3} X A_{3}$, and $A_{5} X A$. (b) Comparison of the preferential cleavage of one glutamic acid, one aspartic acid, two glutamic acids, and two aspartic acid residues from the $b_{8}$ ions of $X_{2} A_{6}, A_{2} X_{2} A_{4}$, and $A_{4} X_{2} A_{2}$ (where $X=E$ or $D$ )

\section{Conclusion}

This systematic study of acidic peptides clearly indicates the occurrence of the head-to-tail cyclization of $b$ ions and related sequence scrambling in CID. The dissociation patterns of the $b_{7}$ ions obtained from the peptides $\mathrm{EA}_{6}, \mathrm{AEA}_{5}, \mathrm{~A}_{2} \mathrm{EA}_{4}, \mathrm{~A}_{3} \mathrm{EA}_{3}$, $\mathrm{A}_{4} \mathrm{EA}_{2}, \mathrm{~A}_{5} \mathrm{EA}$, and $\mathrm{A}_{6} \mathrm{E}$ are completely identical, as are those for the $b_{7}$ ions obtained from the peptides $\mathrm{DA}_{6}, \mathrm{ADA}_{5}, \mathrm{~A}_{2} \mathrm{DA}_{4}$, $\mathrm{A}_{3} \mathrm{DA}_{3}, \mathrm{~A}_{4} \mathrm{DA}_{2}, \mathrm{~A}_{5} \mathrm{DA}$, and $\mathrm{A}_{6} \mathrm{D}$. Similarly, the dissociation patterns of $b_{8}$ ions derived from the peptides $\mathrm{E}_{2} \mathrm{~A}_{6}, \mathrm{~A}_{2} \mathrm{E}_{2} \mathrm{~A}_{4}$, $\mathrm{A}_{4} \mathrm{E}_{2} \mathrm{~A}_{2}$, and $\mathrm{A}_{6} \mathrm{E}_{2}$ are almost the same. The dissociation patterns of $b_{8}$ ions derived from $\mathrm{D}_{2} \mathrm{~A}_{6}, \mathrm{~A}_{2} \mathrm{D}_{2} \mathrm{~A}_{4}, \mathrm{~A}_{4} \mathrm{D}_{2} \mathrm{~A}_{2}$, and
$\mathrm{A}_{6} \mathrm{D}_{2}$ are also identical. It was also clearly shown that the side chains of the acidic residues do not affect the sequence scrambling of the $b$ ions. On the other hand, breakdown graphs show that non-direct sequence $b$ ions are not very abundant during the fragmentation of the $\mathrm{MH}^{+}$ions derived from all of the above peptides, so they do not complicate the $\mathrm{MH}^{+}$spectra very much. It should be mentioned that the abundance of nondirect sequence $b$ ions increases as the collision energy increases.

Additionally, it can be concluded that the residue preference during ring opening is completely dependent on the collision energy applied to dissociate the $b_{7}$ or $b_{8}$ ions. 
The order of glutamic or aspartic acid loss can thus be changed by varying the collision energy for the hepta- and octapeptide series.

To the best of our knowledge, this is the first detailed study where peptides containing acidic residue(s) have been investigated in order to obtain the macrocyclic structures of $b$ ions.

\section{Acknowledgements}

This research was supported by the Scientific and Technological Research Council of Turkey, TUBITAK, under project nos. $109 T 430$ and IYTE 2009 BAP 25. A.E. Atik thanks TUBITAK for a Ph.D. scholarship. The authors also thank Prof. Alex G. Harrison and Assoc. Prof. Veysel Zengin for their valuable comments. The State Planning Organization, DPT, is gratefully acknowledged for its financial support of the Mass Spectrometry Facility.

\section{References}

1. Aebersold, R., Goodlett, D.R.: Mass Spectrom. Proteomics. Chem. Rev. 101, 269-295 (2001)

2. Hunt, D.F., Yates 3rd, J.R., Shabanonowitz, J., Winston, S., Hauer, C. R.: Protein sequencing by tandem mass spectrometry. Proc. Natl. Acad. Sci. U. S. A. 83, 6233-6237 (1986)

3. Medzihradszky, K.F.: Peptide sequence analysis. Meth. Enzymol. 402, 209-244 (2005)

4. Roepstorff, P., Fohlmann, J.: Proposals for a common nomenclature for sequence ions in mass spectra of peptides. Biomed. Mass Spectrom. 11, 601 (1984)

5. Biemann, K.: Contributions of mass spectrometry to peptide and protein structure. Biomed. Environ. Mass Spectrom. 16, 99-111 (1988)

6. Mueller, D.R., Eckersley, M., Richter, W.: Hydrogen transfer reactions in the formation of "Y+2" sequence ions from protonated peptides. Org. Mass Spectrom. 23, 217-222 (1988)

7. Cordero, M.M., Houser, J.J., Wesdemiotis, C.: The neutral products formed during backbone cleavage of protonated peptides in tandem mass spectrometry. Anal. Chem. 65, 1594-1601 (1993)

8. Yalcin, T., Khouw, C., Csizmadia, I.G., Peterson, M.R., Harrison, A.G.: Why are b ions stable species in peptide mass spectra? J. Am. Soc. Mass Spectrom. 6, 1165-1174 (1995)

9. Yalcin, T., Csizmadia, I.G., Peterson, M.R., Harrison, A.G.: The structures and fragmentation of $\mathrm{B}_{\mathrm{n}}(n \geq 3)$ ions in peptide mass spectra. J. Am. Soc. Mass Spectrom. 7, 233-242 (1996)

10. Nold, M.J., Wesdemiotis, C., Yalcin, T., Harrison, A.G.: Amide bond dissociation in protonated peptides. Structures of the Nterminal ionic and neutral fragments. Int. J. Mass Spectrom. Ion Process. 164, 137-153 (1997)

11. Paizs, B., Lendvay, G., Vékey, K., Suhai, S.: Formation of $\mathrm{b}_{2}{ }^{+}$ions from protonated peptides: an ab initio study. Rapid Commun. Mass Spectrom. 13, 525-533 (1999)

12. Harrison, A.G., Csizmadia, I.G., Tang, T.H.: Structures and fragmentation of $\mathrm{b}_{2}$ ions in peptide mass spectra. J. Am. Soc. Mass Spectrom. 11, 427-436 (2000)

13. Bythell, B.T., Erlekam, U., Paizs, B., Maitre, P.: Infrared spectroscopy of fragments from doubly protonated tryptic peptides. Chem. Phys. Chem. 10, 883-885 (2009)
14. Smith, L.L., Hermann, K.A., Wysocki, V.H.: Investigation of gas phase ion structure for proline-containing $\mathrm{b}_{2}$ ion. J. Am. Soc. Mass Spectrom. 17, 20-28 (2006)

15. Perkins, B.R., Chamot-Rooke, J., Yoon, S.H., Gucinski, A.C., Somogyi, A., Wysocki, V.H.: Evidence of diketopiperazine and oxazolone structures of $\mathrm{HA} \mathrm{b}_{2}{ }^{+}$ion. J. Am. Chem. Soc. 131, 17528-17529 (2009)

16. Polfer, N.C., Oomens, J., Suhai, S., Paizs, B.: Spectroscopic and theoretical evidence for oxazolone ring formation in collision-induced dissociation of peptides. J. Am. Chem. Soc. 127, 17154-17155 (2005)

17. Polfer, N.C., Oomens, J., Suhai, S., Paizs, B.: Infrared spectroscopy and theoretical studies on gas-phase protonated leu-enkephalin and its fragments: direct experimental evidence for the mobile proton. J. Am. Chem. Soc. 129, 5887-5897 (2007)

18. Paizs, B., Suhai, S.: Fragmentation pathways of protonated peptides. Mass Spectrom. Rev. 24, 508-548 (2005)

19. Vachet, R.W., Bishop, B.M., Erickson, B.W., Glish, G.L.: Novel peptide dissociation: gas-phase intermolecular rearrangement of internal amino acid residues. J. Am. Chem. Soc. 119(24), 5481-5488 (1997)

20. Yagüe, J., Paradela, A., Ramos, M., Ogueta, S., Marina, A., Barabona, F., Lopez de Castro, J.A., Vazquez, J.: Peptide rearrangement during ion trap fragmentation: added complexity to MS/MS spectra. Anal. Chem. 75, 1524-1535 (2003)

21. Bleiholder, C., Osburn, S., Williams, T.D., Suhai, S., Van Stipdonk, M., Harrison, A.G., Paizs, B.: Sequence-scrambling pathways of protonated peptides. J. Am. Chem. Soc. 130, 17774-17789 (2008)

22. Harrison, A.G., Young, A.B., Bleiholder, C., Suhai, S., Paizs, B.: Scrambling of sequence information in collision-induced dissociation of peptides. J. Am. Chem. Soc. 128, 10364-10365 (2006)

23. Harrison, A.G.: Peptide sequence scrambling through cyclization of $b_{5}$ ions. J. Am. Soc. Mass Spectrom. 19, 1776-1780 (2008)

24. Jia, C., Qi, W., He, Z.: Cyclization reactions of peptide fragment ions during multistage collisionally activated decomposition: an inducement to lose internal amino acid residues. J. Am. Soc. Mass Spectrom. 18, 663-678 (2007)

25. Harrison, A.G.: To $b$ or not to $b$ : the ongoing saga of peptide $b$ ions. Mass Spectrom. Rev. 28, 640-654 (2009)

26. Erlekam, U., Bythell, B.J., Scuderi, D., Van Stipdonk, M., Paizs, B., Maitre, P.: Infrared spectroscopy of fragments of protonated peptides: direct evidence for macrocyclic structures of $\mathrm{b}_{5}$ ions. J. Am. Chem. Soc. 131, 11503-11508 (2009)

27. Riba-Garcia, I., Giles, K., Bateman, R.H., Gaskell, S.J.: Evidence for structural variants of a- and b-type peptide fragment ions using combined ion mobility/mass spectrometry. J. Am. Soc. Mass Spectrom. 19, 609-613 (2008)

28. Molesworth, S., Osburn, S., Van Stipdonk, M.: Influence of size on apparent scrambling of sequence during CID of b-type ions. J. Am. Soc. Mass Spectrom. 20, 2174-2181 (2009)

29. Harrison, A.G.: Cyclization of peptide $b_{9}$ ions. J. Am. Soc. Mass Spectrom. 20, 2248-2253 (2009)

30. Bythell, B.J., Knapp-Mohammady, M., Paizs, B., Harrison, A.G.: Effect of the His residue on the cyclization of b ions. J. Am. Soc. Mass Spectrom. 21, 1352-1363 (2010)

31. Molesworth, S., Van Stipdonk, M.: Apparent inhibition by arginine of macrocyclic $\mathrm{b}$ ion formation from singly charged protonated peptides. $J$. Am. Soc. Mass Spectrom. 21, 1322-1328 (2010)

32. Reid, G.E., Simpson, R.J., O'Hair, R.A.J.: Probing the fragmentation reactions of protonated glycine oligomers via multistage mass spectrometry and gas phase ion molecule hydrogen/deuterium exchange. Int. J. Mass. Spectrom. 190/191, 209-230 (1999)

33. Ballard, K.D., Gaskell, S.J.: Dehydration of peptide $[\mathrm{M}+\mathrm{H}]^{+}$ions in the gas phase. J. Am. Soc. Mass Spectrom. 4, 477-481 (1993)

34. Molesworth, S., Osburn, S., Van Stipdonk, M.: Influence of amino acid side chains on apparent selective opening of cyclic $\mathrm{b}_{5}$ ions. J. Am. Soc. Mass Spectrom. 21, 1028-1036 (2010) 